\title{
Knowledge, Curiosity, Communication Channels and Panic during COVID-19 Movement Control Order
}

\author{
Ali Salman \\ ali.salman@umk.edu.my \\ Faculty for Language Studies and Human Development \\ Universiti Malaysia Kelantan
}

\begin{abstract}
With the accelerated dissemination of the worldwide COVID-19 pandemic, people around the world were and still are expressing fear and panic in diverse behaviors. Media and Communication Channels as carriers of news on COVID-19 might have a role in spreading panic among the population. This study was conducted to determine the media and communication channels responsible for creating panic among Malaysians during COVID-19 Movement Control Order (MCO). The study employed a quantitative approach. A survey using questionnaire was used to collect data from 253 respondents across Malaysia. The findings revealed that in terms of media and communication channels, most of the respondents reported that they panic due to the exposure to reports from online media (Internet and social media). This is followed by communication with family members. Television, radio and newspaper reports are the third contributors of panic among Malaysians during COVID-19 MCO. Meanwhile about half of the respondents said they panic because of curiosity about COVID19. It is an irony that online media, which contributes to the panic is also a source of information on COVID-19 and platform to work from home. A proposed framework should include the use of social media to direct people to trusted sources during pandemic.
\end{abstract}

Keywords: Media; communication channels; COVID-19; Movement Control Order; panic

\section{INTRODUCTION}

In late December 2019, a novel coronavirus disease (COVID-19) was reported to spread from Wuhan, China that eventually affected 200 countries worldwide (Xu et al., 2020). With the accelerated dissemination of the worldwide COVID-19 pandemic, people around the world were and still are expressing fear and panic in diverse behaviors. Positive confirmed cases and death toll are increasing daily, spanning over 200 countries, where both numbers, as of 20 April 2020, have surpassed 2 million and 100,000 cases, respectively (WHO, 2020). It has not only effected the economy of different countries but also had global impacts on social values and psychological stress of the people involved. Such pandemic effects also influence human behavior; issues of panic buying (overbuying) and noncompliance with government orders and law (Teck Ling and Chyong Ho, 2020). Panic and fear are emotions that mobilize energy to deal with threats by triggering safety behaviors. For instance, when fear is too excessive, this may have detrimental effects both at the individual level and at the societal level (Mertens et al., 2020). Issues of panic buying have surfaced all around the world causing disputes to the 
supply chain and food insecurities among individuals with low socioeconomic status and other vulnerable populations (Tasnim et al., 2020).

With unparalleled interruption of the everyday lives of billions of people worldwide, the pandemic has also reiterated the importance of coordination in finding sufficient public reaction to effectively introduce public health measures to stem the outbreak (Hanafiah and Wan, 2020). This crisis has attracted intense media attention. In the modern age, the proliferation of the network and social media has radically altered the distribution of information (Wen et al., 2020). A particularity of this pandemic was the coincidence of virology and virality: not only did the virus spread very rapidly, but so did the informationand misinformation-about the outbreak and thus the panic that it created among the public (Depoux et al., 2020). The information spreading can strongly influence people behavior and alter the effectiveness of the countermeasures deployed by governments (Cinelli et al., 2020). The misinformation regarding the pandemic is masking healthy (such as hand washing, social distancing etc.) behaviors and promoting misguided practices that increase the spread of the virus and ultimately result in poor physical and mental health outcomes among individuals (Tasnim et al., 2020). The hoaxes that surfaced on various social media platforms regarding the prevention and cure of COVID-19 have damaged the news ecosystem (Tasnim et al., 2020). The risk of misinformation surrounding the pandemic has motivated the World Health Organization (WHO) to launch a "Mythbuster" page, as well as partner with social media platforms like Facebook, Google, LinkedIn, Microsoft, Reddit, Twitter, and YouTube to dissolve the misinformation. Clear messages with clear language about what is needed to prevent spread of the virus are critical (Ventriglio et al., 2020).

Efforts to contain the pandemic, numerous scientific clinical trials and medical research have been undertaken, aiming to develop vaccines to treat the disease, as well as government interventions (e.g., social distancing policies, quarantines, movement control orders, travel restrictions, and lockdowns) are in place to 'flatten the curve' and mitigate the economic situation (Teck Ling and Chyong Ho, 2020). However, the effectiveness of these control measures is highly dependent on cooperation and compliance of all members of society. This cooperation and compliance is highly based on the knowledge, attitudes and practices people hold toward the disease (Azlan et al., 2020).

The chronic nature of the epidemic of coronavirus disease (COVID-19) and lack of cure is creating an atmosphere that is critical for mental well-being. The COVID-19 pandemic situation has also threatened the well-being of children and families due to the emerging financial challenges and isolation stress. Social-distancing and self-isolation has challenged all the aspects of mental health, wellbeing, emotional health, psychological and social wellness at the collective level (Mukhtar, 2020). This period of unemployment for a large population around the world had temporarily caused an intense level of grief and trauma among families (Blustein et al., 2020). Such fear can be discussed by simple, concise communications regarding the disorder and its future sequel, rather than ambiguous pronouncements (Ventriglio et al., 2020). Where the situation has had negative impacts on family setting, on the other hand it has also reframed the daily lives by allowing people to be more mindful, focus on personal growth, building resilience and adopting new behaviors, such as hand-washing, healthy diet and physical activity (Mukhtar, 2020). It is times like this that we need social and emotional closeness with those in families, our friends, peers and colleagues (Ventriglio et al., 2020).

Malaysia and neighboring Southeast Asian countries, such as Thailand and Singapore, were among the first few countries to report COVID-19 cases outside of China (Hanafiah and Wan, 2020). In Malaysia, The first wave of infection started on 24 January 2020, with the identification of 22 cases. There were 11 days with no cases, from 16 to 26 February 2020. After the first wave, The WHO advised Malaysian health authorities to be prepared for a larger 
spread of infection and ensure that health facilities can treat most susceptible and serious cases (Shakeel et al., 2020). The second wave began on 27 February 2020 and is still ongoing (WHO, 2020).

Malaysia was one of the first countries to respond swiftly to protect its people from COVID-19. The main objective was to minimize the economic and social impacts, to limit their spread and to provide care for their citizens (Shah et al., 2020). Lockdown measures were perceived as necessary to curb the spread of the virus due to which a movement control order (MCO) was enforced in Malaysia on the $18^{\text {th }}$ of March, 2020. \#stayhome was widely used in the media to stop COVID-19 from spreading can reach every level of society (Shah et al., 2020). The MCO prohibited all visitors and residents from traveling abroad, closing all places of worship, schools and business premises excluding essential services. Malaysia, like many countries also had the issue of spread of false information, such as false reports of infected individuals in various locations and unverified remedies to cure the infection (Hanafiah and Wan, 2020). Many contributions were made by the citizens and as well as the mainstream and social media.

Based on the situations that occurred due to the pandemic, the objective of this paper is to determine the extent of panic caused by information about COVID-19 obtained from media, colleagues and families among Malaysians. The paper will also look at what the people do during the MCO and how they rate the government and front liners.

\section{LITERATURE REVIEW}

The general population 's psychosocial reactions to recent outbreaks of infectious disease over the past two decades (such as the Extreme Acute Respiratory Syndrome (SARS) epidemic, H1N1 pandemic, Ebola virus epidemics) have been recorded across the globe include fears and anxiety, sadness, uncertainty, shame, irritability, sense of alienation and stigma (Sim et al., 2020). The exponential increase in social media and digital connectivity since earlier outbreaks of SARS/MERS, H1N1 pandemic fuels the propagation and contagion of such psychological responses (Depoux et al., 2020). Today, media sources are critical for supplying accurate news reports to the public. Professional and timely monitoring of these outlets on regional emergencies or incidents is required (Wen et al., 2020).

Since the emergence of COVID-19, there tends to be strong audience involvement in both the production and distribution of information in the form of videos and social media messages, rather than the mere distribution by conventional authority (public) and specialists, who still use various platforms such as social media and live streaming (Hanafiah and Wan, 2020). Social media should be used to disseminate reliable information about when to get tested, what to do with the results, and where to receive care (Merchant and Lurie, 2020). An analysis of headlines regarding the COVID-19 outbreak showed that a large number of them have negative sentiments and emotional weight. Due to this, the fear associated with death cases is a pandemic that has created emergency and panic not only in Wuhan but across the borders of China (Aslam et al., 2020).

Information and news reports about the coronavirus disease (COVID-19) were rapidly published and shared on social media and social networking sites. The COVID-19 pandemic has been referred to as the first social media infodemic (Ahmad and Murad, 2020). However, there is limited evidence about whether and how the social media infodemic has spread panic and affected the mental health of social media users. Relying on information on social media can also intensify fear, frustration, panic and paranoia (Ventriglio et al., 2020). It is crucial that only reliable sources of information are accessed. The researchers aimed to determine how social media affects self-reported mental health and the spread of panic about COVID-19 in the Kurdistan Region of Iraq. A total of 516 social media users were sampled for the study. 
Participants reported that social media has a significant impact on spreading fear and panic related to the COVID-19 outbreak in Iraqi Kurdistan, with a potential negative influence on people's mental health and psychological well-being. Facebook was the most used social media network for spreading panic about the COVID-19 outbreak in Iraq. There was a significant positive statistical correlation between self-reported social media use and the spread of panic related to COVID-19. It implies that during lockdown, people are using social media platforms to gain information about COVID-19. On one hand, social media has played a key role in spreading anxiety about the COVID-19 outbreak in Iraqi Kurdistan.

While on the other hand, in China, consumption of digital media (social media, mobile social networking apps, online news media, and social live steaming services) has also encouraged preventive behavioural changes - directly or indirectly. People were found to practice washing their hands more regularly with soap and water, staying away from crowded places, disinfecting household surfaces and wearing face masks out in public. The study results also showed that consumption of digital media triggers worry among individuals which then leads to acceptance and implementation of preventive measures (Liu, 2020).

Panic caused by media was also experienced during the Ebola outbreak. During times of hot crises, traditional news organizations have historically contributed to public fear and panic by emphasizing risks and uncertainties (Kilgo et al., 2020). The degree to which digital and social media platforms contribute to this panic is essential to consider in the new media landscape. False information on social media consists of intentionally fabricated stories that are routinely generated to publicize certain agenda (Yusof et al, 2020). The authors (Kilgo et al., 2020) set out to examine news coverage of the 2014 Ebola crisis, exploring differences in presentation between newspaper coverage and news shared on the social news platform Reddit. Results suggest that news shared on Reddit amplified panic and uncertainty surrounding Ebola, while traditional newspaper coverage was significantly less likely to produce panic-inducing coverage. Moreover, dissemination of inaccurate information during pandemic can lead society members to resort to any measures which in their opinion may protect them. Left unchecked, information that reaches the public can cause public uproar and may cause unnecessary fear to the public (Yusof et al, 2020). However, the authors also suggested that following only verified sources and organizations should be a priority. In Malaysia, the public now has easy access in obtaining official updates from the relevant authorities via social media platforms such as those of the Ministry of Health (MoH) Crisis Preparedness and Response Centre (CPRC) and the National Security Council Facebook pages and Telegram channels (Yusof et al, 2020).

Studies on pandemic are not new. They date back to many years ago focusing on containing the spread and developing vaccines to prevent and cure pandemic outbreak. As we shall see, studies on pandemic in relation to role or function of online media are scarce. Seasonal epidemic influenza continues to cause worldwide disease and death on a yearly basis, and current vaccines offer sub-optimal protective immunity (Crank et al., 2020). The authors reviewed the scientific opportunities for developing influenza vaccines with broad coverage, commonly referred to as "universal" influenza vaccines, that would better protect us against the global burden of seasonal epidemics and offer the potential to protect us from a 1918-like pandemic event. The researchers attested that new vaccines are often derived by exploiting new technologies. Crank et al. (2020) provided some clear pathways to explore and knowledge gaps to fill in the immediate future using currently available technology. Among them is by harnessing high-throughput sequencing and computational biology, more sophisticated algorithms based on sequence analysis, glycan patterns, and other features that may anticipate high transmissibility, can be developed for predicting the next dominant strain. They also suggested improving strain selection for seasonal vaccines as this would 
increase the likelihood of an antigenic match between the vaccine and dominant circulating strains and thereby improve the utility of current vaccine technology.

Many of us are in uncharted territory and have never experienced such a pandemic during our lifetimes. The COVID-19 pandemic is the first to occur in an age of hyperconnectivity (Hanafiah and Wan, 2020). Planning is critical to mitigating the sudden and potentially catastrophic impact of an infectious disease pandemic on society (Shearer et al., 2020). They observed that national pandemic policy documents cover a wide variety of control options, often with nonspecific recommendations for action. Despite advances in analytical methods for gaining early situational awareness (i.e., of a disease's transmissibility and severity) and for predicting the likely effectiveness of interventions, a major gap exists globally in terms of integrating these outputs with the advice contained in policy documents. The researchers observed that decision models provide an approach to defining and evaluating alternative policy options under complex and changing conditions. A decision model for infectious disease pandemics is an appropriate method for integrating evidence from situational and intervention analysis tools, along with the information in policy documents, to provide robust advice on possible response options (including uncertainty). However, a decision model for pandemic response cannot capture all of the social, political, and ethical considerations that impact decision-making. Such a model should therefore be embedded in a decision support system that emphasizes this broader context.

The COVID-19 pandemic has raised challenges in dealing with information sharing by the public and the authorities. Using online social networks to track a pandemic, a systematic review of the use of Online Social Networks (OSNs) was conducted (Al-Garadia et al., 2020). The researchers conducted a systematic literature search for studies with the primary aim of using OSN to detect and track a pandemic. The found out that OSNs have rich information that can be utilized to develop an almost real-time pandemic surveillance system. They identified the extent of using OSNs to track a pandemic and concluded that OSNs contain significant information to track a pandemic almost in real time.

In the face of COVID-19, social media is a great way for individuals and communities to stay connected even while physically separated. With the advent of social media in the $21 \mathrm{st}$ century, not only are we learning the latest news updates, but we're also using platforms like Facebook and Twitter to provide personal and business updates (Kushner, 2020). For businesses, this means leveraging social media to support employees and customers like never before. For the government, it means doing its best to efficiently share factual and up-to-date information. (Kushner, 2020) By observing how individuals, businesses, and government agencies have been sharing information and interacting with others on social media during COVID-19 pandemic, outline four primary roles that social platforms are playing during the outbreak. This include, as a source of information (and misinformation), an influence on public response to the outbreak, a marketing platform and a powerful way to bring positivity to a scary time.

However, during the Covid-19 outbreak, the term fake news is so common, which contain incorrect data and provide false tips and advice. Hoaxed news is no longer distributed via conventional news media like print and television, but instead exploded online through social media platforms. According to the Malaysian Correspondence and the Multimedia Committee, $99 \%$ of the identified false news distributed in Malaysia came from local people who used fictitious or anonymous accounts. The negative phenomenon can be restrained by improved supervision of social media platforms and educating the public to visit fact-checking websites and avoid being influenced by others easily (Mohammad Din et al., 2020). 
A cross-sectional online survey of 4,850 Malaysian residents showed that most of the participants held positive attitudes toward the successful control of COVID-19, the ability of Malaysia to conquer the disease and the way the Malaysian government was handling the crisis. The results also indicated that high number of participants had correct knowledge of COVID19 because of health authorities consistently disseminating COVID-19 information since the disease was first detected in Malaysia. However, the results also indicated several participants did not have correct knowledge probably due to the surge of inaccurate information that can cause immense confusion. Additionally, the results of an analytic study identified 15 Facebook postings with positive messages, posted by Malaysians during the Movement Control Order (MCO). The findings suggested high level of solidarity and empowerment among Malaysians. This shows individual efforts in positively communicating correct information with mutual goals and hopes that have subsequently acted as a strong buffer against negative discourse (Azizan et al., 2020). Furthermore an anonymous survey was conducted to examine public knowledge, perception and communication behaviour among Malaysians in the early stages of Movement Control Order in Malaysia. The results showed that Malaysian had high level of knowledge regarding risk perception and positive communication behaviour. $95 \%$ of Malaysian respondents agreed that the information they receive strongly influenced their behaviour. However, majority of the population was receiving inaccurate or questionable information (Hanafiah and Wan, 2020).

During the pandemic period, Malaysians have also displayed a variety of behaviour changes including panic buying, mass travelling during movement restriction and even absconding from treatment facilities. The study findings of (Boon Yau et al., 2020) suggested that the particular behaviour changes are often influenced by the company and associations of the individual. The also seemed to be shaped by the goals of the individual, whether this is to avoid illness, avoid anxiety or to live by important life values (Boon Yau et al., 2020).

Unlike the older and more traditional media, today, many methods of sharing information have been subsumed by giant social media platforms that have incredible speed, reach, and penetration (Merchant and Lurie, 2020). Such as, the Facebook Preventive Health tool provides individuals with vetted guidelines about preventive health recommendations and then directs users to geo-targeted locations where these services are available (Merchant and Lurie, 2020). The researchers posited that current understanding of how these platforms can be harnessed to optimally support emergency response, resilience, and preparedness is not well understood. They outline a framework for integrating social media as a critical tool in managing the current evolving pandemic as well as transforming aspects of preparedness and response for the future. The framework include the use of social media to direct people to trusted sources, to counteract misinformation, as a diagnostic tool and referral system, to enable connectivity and psychological First Aid, to advance remote learning, to accelerating research, to enable a culture of preparedness.

\section{METHOD}

The study employed a quantitative approach. An online survey method was used to collect data. The questionnaire was developed on Google document and distributed to respondents via WhatsApp and email. Simple random sampling was used to sample 253 respondents across Malaysia. Data collection was done from the third to fifth week of the MCO. The age group comprise $19-24 ; 25-30 ; 31-35 ; 36-40 ; 41$ and above. The data was analysed based on descriptive statistics using SPPS software.

\section{FINDINGS AND DISCUSSIONS}


This section is divided into three, COVID-19 and panic, activities done at home during the MCO and satisfaction towards the measures taken by the authorities.

\section{COMMUNICATION CHANNELS, COVID-19 AND PANIC}

Social media has become central stage in spreading information. During pandemics, social media is seen as playing a major role in spreading information about pandemic, which has been termed as social media infodemic. From the results of this study, $43.5 \%$ of the respondents reported panic because of the online media reports (Internet; social media). The finding concurs with Tasnim et al (2020) where participants reported that social media has a significant impact on spreading fear and panic related to the COVID-19 outbreak. Moreover, in addition to reporting, the lack of proper messaging and reports of an outbreak of a novel disease causes panic (Tasnim et al., 2020). Meanwhile 31.2\% of the respondents said they panic because of report by family members. This is followed by $27.7 \%$ of the respondents who said they panic because of reports by conventional media (TV; Radio; Newspapers). This finding is in line with the finding by (Kilgo et al., 2020) that during times of hot crises, traditional news organizations have historically contributed to public fear and panic by emphasizing risks and uncertainties. Reports from colleagues and friends (26.5\%) are the least cause of panic among the media and interpersonal communication channels.

In addition to media and communication channels, $51.4 \%$ respondents said they panic because of curiosity to know more about COVID-19. This is some sort of unnecessary panic driven by curiosity. The "knowledge" that COVID-19 is dangerous $(79.1 \%)$ is the highest contributor of panic among the respondents. The knowledge that the pandemic is dangerous and curiosity to know are the main cause of concern as Table 1 shows. The two have the highest mean of 5.53 and 3.59 respectively. The knowledge about the pandemic by the respondents could be understood to mean a lack of knowledge as it might have been built by media and interpersonal communication hype. This has been proven by earlier and latest studies. The current lack of knowledge and poor communication has been attributed as a precursor to the skyrocketing global panic (Tasnim et al., 2020).

Table 1. Panic Due to Reports by Media and Interpersonal Communication Channels

\begin{tabular}{|l|l|l|l|}
\hline No. & Items & Mean* & Level of Effect** \\
\hline 1 & $\begin{array}{l}\text { I panic because of the knowledge that } \\
\text { dangerous. }\end{array}$ & 5.53 & High \\
\hline 2 & I panic because of curiosity to know more about COVID-19 & 3.59 & Average \\
\hline 3 & $\begin{array}{l}\text { I panic because of the online media reports (Internet; social } \\
\text { media). }\end{array}$ & 3.04 & Average \\
\hline 4 & I panic because of report by family members. & 2.18 & Low \\
\hline 5 & $\begin{array}{l}\text { I panic because of reports by conventional media (TV; } \\
\text { Radio; Newspapers). }\end{array}$ & 1.93 & Low \\
\hline 6 & I panic because of reports from colleagues and friends. & 1.85 & Low \\
\hline$* 1$ (Strongly Disagree) - 7 (Strongly Agree) \\
$* * 1-2.99=$ Low; 3- 4.99= Average; 5- 7 = High
\end{tabular}

\section{ACTIVITIES AT HOME DURING MCO}

The MCO is accompanied by a partial lockdown restricting movement among the population. Whilst at home, the people engaged in various activities. Almost all the respondents (96\%) said they used social media to get information about COVID-19. Social media has now become handy source of information. This is confirmed by (Blustein et al., 2020) who assert that during 
lockdown, people are using social media platforms to gain information about COVID-19. Second in the list of activities done at home during MCO was talking with family $(91.3 \%)$. The MCO provided the opportunity for quality time with the family strengthening ties. This is followed by cooking (84.2\%). Malaysians, especially the working class, who mainly eat outside became chefs during MCO since movement was restricted and a large number of restaurants were closed. Religiosity increased during the MCO as Malaysians (79.4\%) turned to God to seek solace by reading religious books. Other activities included, Work (online) From Home (57.3\%), watching TV (52.6\%), sleep more (47\%) and reading storybooks $(39.1 \%)$.

\section{SATISFACTION WITH THE MEASURES TAKEN BY THE AUTHORITIES}

In fighting to curb the pandemic from spreading widely among the population, in addition to the MCO, the authorities and health workers became the front liners in enforcing the SOP on COVID-19 and treating patients who have caught the disease. Almost all the respondents (98.85) were satisfied with the way the doctors and nurses performed their duties. This is followed by $95.7 \%$ of the respondents who were satisfied with the police and army saying they were professional in carrying out their duties. The Malaysian government was praised by the people as most of them (95.3\%) agree the government did well in combating the spread of COVID-19. Further, a large number (93.7\%) also said they are satisfied with the action taken by the government and front liners in combating the spread of the pandemic.

\section{CONCLUSION}

In summary, the present study was able to provide a comprehensive explanation of the knowledge, attitudes and practices of Malaysians toward COVID-19 Movement Control Order. The findings suggested that internet and Social Media added to the panic, but at the same time came to the rescue by providing information on the pandemic. It also showed that Malaysians generally comported themselves very well during the MCO and largely turned to God for solace. In terms of personal relations and activities, the findings suggested that family ties became closer while providing additional opportunities to practice and learn new hobbies. Even so, consistent messaging from the government and health authorities were key to satisfaction among Malaysians. Additionally, Malaysia was among the top 5 countries for effectively handling COVID-19. This study suggests that understanding social dynamics behind content consumption on social media and various communication channels is an important topic, as it can help develop more efficient disease models that account for social behaviour, and introduce more successful communication strategies in times of health crisis and pandemic. For future actions in such pandemic conditions, implementation of earlier MCO and more stringent measures will ensure sound mental health of the public. It will also reduce community panic and unhelpful measures disproportionate to the cause. A proposed framework should include but not limited to the use of social media to direct people to trusted sources and to counteract misinformation and fake news during pandemic.

\section{REFERENCES}

Ahmad, A., \& Murad, H. (2020). The Impact of Social Media on Panic During the COVID19 Pandemic in Iraqi Kurdistan: Online Questionnaire Study. Journal of Medical Internet Research, 22(5), e19556. https://doi.org/10.2196/19556

Al-garadi, M., Khan, M., Varathan, K., Mujtaba, G., \& Al-Kabsi, A. (2016). Using online 
social networks to track a pandemic: A systematic review. Journal of Biomedical Informatics, 62, 1-11. https://doi.org/10.1016/j.jbi.2016.05.005

Aslam, F., Awan, T., Syed, J., Kashif, A., \& Parveen, M. (2020). Sentiments and emotions evoked by news headlines of coronavirus disease (COVID-19) outbreak. Humanities and Social Sciences Communications, 7(1).https://doi.org/10.1057/s41599-020-0523-3

Azizan, M., Ismail, H., \& Qaiwer, S. (2020). Power and solidarity in positive Facebook postings amidst covid-19 in Malaysia. Journal of Nusantara Studies (JONUS), 5(2), 329-364. https://doi.org/10.24200/jonus.vol5iss2pp329-36

Azlan, A., Hamzah, M., Sern, T., Ayub, S., \& Mohamad, E. (2020). Public knowledge, attitudes and practices towards COVID-19: A cross-sectional study in Malaysia. PLOS ONE, 15(5), e0233668. https://doi.org/10.1371/journal.pone.0233668

Blustein, D., Duffy, R., Ferreira, J., Cohen-Scali, V., Cinamon, R., \& Allan, B. (2020). Unemployment in the time of COVID-19: A research agenda. Journal of Vocational Behavior, 119, 103436. https://doi.org/10.1016/j.jvb.2020.103436

Boon Yau, E., Tze Ping, N., Shoesmith, W., James, S., Nor Hadi, N., \& Jiann Lin, L. (2020). The Behaviour Changes in Response to COVID-19 Pandemic within Malaysia. Malaysian Journal Of Medical Sciences, 27(2), 45-50. https://doi.org/10.21315/mjms2020.27.2.5

Cinelli M, Quattrociocchi W, Galeazzi A, Valensise C, Scala A. (2020). The COVID-19 Social Media Infodemic, 1-18.

Crank, M., Mascola, J., \& Graham, B. (2019). Preparing for the Next Influenza Pandemic: The Development of a Universal Influenza Vaccine. The Journal Of Infectious Diseases, 219(Supplement_1), S107-S109. https://doi.org/10.1093/infdis/jiz043

Depoux, A., Martin, S., Karafillakis, E., Preet, R., Wilder-Smith, A., \& Larson, H. (2020). The pandemic of social media panic travels faster than the COVID-19 outbreak. Journal of Travel Medicine, 27(3). https://doi.org/10.1093/jtm/taaa031

Hanafiah, K., \& Chang Da Wan, C. (2020). Public knowledge, perception and communication behavior surrounding COVID-19 in Malaysia.

Kilgo, D., Yoo, J., \& Johnson, T. (2018). Spreading Ebola Panic: Newspaper and Social Media Coverage of the 2014 Ebola Health Crisis. Health Communication, 34(8), 811817. https://doi.org/10.1080/10410236.2018.1437524

Kushner, J. (2019). The role of social media during a pandemic | Khoros. Khoros |Digital care, communities, \& social media software. Retrieved 12 September 2020, from https://khoros.com/blog/social-medias-role-during-covid-19.

Liu, P. (2020). COVID-19 Information Seeking on Digital Media and Preventive Behaviors:

The Mediation Role of Worry. Cyberpsychology, Behavior, and Social Networking. https://doi.org/10.1089/cyber.2020.0250

Merchant, R., \& Lurie, N. (2020). Social Media and Emergency Preparedness in Response to Novel Coronavirus. JAMA, 323(20), 2011. https://doi.org/10.1001/jama.2020.4469

Mertens, G., Gerritsen, L., \& Duijndam, S. (2020). Fear of the coronavirus (COVID-19): Predictors in an online study conducted in March 2020. Journal of Anxiety Disorders, 74, 102258. https://doi.org/10.1016/j.janxdis.2020.102258

Mohamed Din, M., Nadhirah Kamal, N., \& Abdullah, A. (2020). Fake News on Social Media During Covid-19 Crisis, 19-30. Retrieved 11 September 2020, from.

Mukhtar, S. (2020). Mental Health and Psychosocial Aspects of Coronavirus Outbreak in Pakistan: Psychological Intervention for Public Mental Health Crisis. Asian Journal of Psychiatry, 51, 102069. https://doi.org/10.1016/j.ajp.2020.102069

Mukhtar, S. (2020). Pakistanis' mental health during the COVID-19. Asian Journal of 
Psychiatry, 51, 102127. https://doi.org/10.1016/j.ajp.2020.102127

Shah, A., Safri, S., Thevadas, R., Noordin, N., Rahman, A., \& Sekawi, Z. et al. (2020).

COVID-19 outbreak in Malaysia: Actions taken by the Malaysian government. International Journal Of Infectious Diseases, 97, 108-116. https://doi.org/10.1016/j.ijid.2020.05.093

Shakeel, S., Ahmed Hassali, M., \& Abbas Naqvi, A. (2020). Health and Economic Impact of COVID-19: Mapping the Consequences of a Pandemic in Malaysia. Malaysian Journal of Medical Sciences, 27(2), 159-164. https://doi.org/10.21315/mjms2020.27.2.16

Shearer, F., Moss, R., \& McVernon, J. (2020). Infectious disease pandemic planning and response: Incorporating decision analysis. PLOS Medicine, 17(1), e1003018. https://doi.org/10.1371/journal.pmed.1003018

Sim, K., Chua, H., Vieta, E., \& Fernandez, G. (2020). The anatomy of panic buying related to the current COVID-19 pandemic. Psychiatry Research,288, 113015. https://doi.org/10.1016/j.psychres.2020.113015

Tasnim, S., Hossain, M., \& Mazumder, H. (2020). Impact of Rumors and Misinformation on COVID-19 in Social Media. Journal of Preventive Medicine And Public Health, 53(3), 171-174. https://doi.org/10.3961/jpmph.20.094

Teck Ling, G., \& Chyong Ho, C. (2020). Effects of the Coronavirus (COVID-19) Pandemic on Social Behaviours: From a Social Dilemma Perspective. Technium Social Sciences Journal, 7, 312-320. Retrieved 12 September 2020, from.

Ventriglio, A., Watson, C., \& Bhugra, D. (2020). Pandemics, panic and prevention: Stages in the life of COVID-19 pandemic. International Journal of Social Psychiatry, 66(8), 733-734. https://doi.org/10.1177/0020764020924449

Wen, J., Aston, J., Liu, X., \& Ying, T. (2020). Effects of misleading media coverage on public health crisis: a case of the 2019 novel coronavirus outbreak in China. Anatolia, 31(2), 331-336. https://doi.org/10.1080/13032917.2020.1730621

World Health Organisation. (2020). COVID-19 SITUATION OVERVIEW IN MALAYSIA.

Xu, Z, Shi, L., Wang, Y., Zhang, J., Huang, L., \& Zhang, C., Liu, S., Zhao, P. (2020). Pathological findings of COVID-19 associated with acute respiratory distress syndrome. The Lancet Respiratory Medicine, 8(4), 420-422. https://doi.org/10.1016/s2213-2600(20)30076-X

Yusof, A., Muuti, M., Ariffin, L., \& Tan, M. (2020). Sharing Information on COVID-19: the ethical challenges in the Malaysian setting. Asian Bioethics Review, 12(3), 349-361. https://doi.org/10.1007/s41649-020-00132-4

\section{About the authors}

Assoc. Prof. Dr. Ali Salman is a senior lecturer and researcher at the Department of Humanities, Faculty of Language Studies and Human Development, Universiti Malaysia Kelantan. Dr. Ali has conducted substantial research relating to New Media and Digital Inclusion. He has extensively published his work in SCOPUS and ISI journals throughout his academic career, which has spanned for more than a decade. Ali frequently features in local newspapers where he shares his research findings. He has been invited as external examiner for $\mathrm{PhD}$ and Masters' thesis and he is an external program reviewer for few institutions. Ali is currently the Chief Editor for Journal Insaniah and is also serving as an editorial board member and associate editor for various academic journals including Journal of Asia Pacific Communication (JAPC) and has served as a Chief Editor for eBangi journal for five years. Email: ali.salman@umk.edu.my; asalmanphd@gmail.com 